\title{
De tiranos e oprimidos: uma leitura de Animal Farm ao longo da linha do tempo
}

\author{
José Evandro Martins Paz
}

\begin{abstract}
Resumo: Textos literários estão, muitas vezes, intrinsecamente relacionados com o contexto social no qual foram produzidos. Por essa razão, é importante analisar as influências desses aspectos externos dentro da obra, isto é, torna-se necessário entender como esse processo se dá e como isso interfere na construção de sentido do discurso ficcional. Animal Farm é um importante exemplo da conexão entre contexto social e literatura, pois evidencia traços do contexto histórico e ideológico da época em que foi escrito. Este trabalho objetiva analisar como esse romance dialoga com o seu contexto de origem, e como, simultaneamente, permite uma abordagem atemporal em diferentes contextos relacionados a outras sociedades.
\end{abstract}

Palavras chave: Autoritarismo; Contexto social; Literatura.

\begin{abstract}
Literary texts are often intrinsically related to the social context in which they were produced. Due to this reason, it is important to analyze the influences of these external aspects

within the work, that is, it is necessary to understand how this process takes place and how this interferes with the construction of sense in the fictional speech. Animal Farm is a relevant example of the connection between social context and literature, once it manifests features of the historical and ideological contexts concerning the time the book was written. This article aims at analyzing how this novel interacts with its source context and how it simultaneously allows us to suggest a perennial approach in different contexts related to other societies.
\end{abstract}

Keywords: Authoritarianism; Social context; Literature.

\section{Introdução}

A obra Animal Farm de George Orwell foi publicada em 1945, isto é, após o término da Segunda Guerra Mundial. George Orwell (Eric Arthur Blair) nasceu em 1903 na Índia e mudou-se para a Inglaterra em 1907. No ano de 1921, partiu da Inglaterra e, em 1922, começou a trabalhar para a polícia Imperial Indiana, na qual serviu até 1928. Lá ele se deparou com as manifestações autoritárias e repressivas contra o povo e a liberdade, o que viria posteriormente a influenciar suas produções literárias.

Em 1945, Orwell se tornou um correspondente de Guerra e mais tarde viria a contribuir regularmente com Jornal Manchester Evening News. Suas obras mais famosas são

\footnotetext{
* José Evandro Martins Paz é graduado em Letras- Habilitação Português/Inglês pela Universidade Federal de Santa Maria. É graduando em Engenharia Química na mesma Instituição. Participa de um projeto de pesquisa Departamento de Letras Vernáculas do curso de Letras da UFSM e orientado pela Prof. ${ }^{a}$ Dr. Silvia Nascimento.
} 
Animal Farm e 1984, duas obras que representam à realidade possível e assustadora de sistemas autoritários.

Convêm ressaltar que George Orwell não teve a pretensão de escrever seus textos como obras de ficção literária; sua intenção era a de satirizar e denunciar os governos e regimes totalitários existentes na época e, com os quais, havia se deparado durante sua vida.

\section{Sobre a obra Animal Farm}

O romance Animal Farm é a história, como se fosse uma fábula, de uma revolução que deu errado, isto é, alguns animais de uma determinada fazenda, Fazenda Manor, devido aos maus tratos e às más condições de vida que recebiam, resolveram se rebelar e tomar o controle da mesma. Assim o fizeram e estabeleceram, num primeiro momento, uma sociedade com modelos próprios de ideologia, cultura e sistema sócio-político. Os animais escolheram um líder e governante da fazenda para ocupar o lugar do fazendeiro - escolheram um porco: Napoleão.

O problema é que a doutrina inicial da nova sociedade foi sendo alterada ao longo do desenvolvimento do novo modelo social e, na medida em que essas alterações eram feitas, apareceram várias justificativas criadas por parte dos novos governantes, os porcos, os quais se tornaram tiranos, autoritários e repressores. O romance é considerado uma sátira ao autoritarismo dos regimes totalitários e possui certas dimensões sociais que são facilmente identificáveis, partindo-se de um conhecimento prévio do leitor em relação ao contexto histórico-social da época em que foi produzido, isto é, um período marcado por resquícios da Primeira Guerra Mundial e da crise econômica de 1929, que ainda assolava a maioria das nações do mundo. Além disso, esse momento foi marcado pelas revoluções russas (Menchevique, Bolchevique) que levaram a queda do czarismo na Rússia e a instalação de um novo modelo - Socialismo - através do governo de Lênin. Esse governo pregava novas políticas sociais e econômicas, instituindo a União das Repúblicas Socialistas Soviéticas (URSS). Porém, com a morte de Lênin, em 1924, o poder soviético foi disputado por Leon Trotski, chefe do exército, e Josef Stálin, secretário-geral do Partido comunista.

Stalin saiu vitorioso e, nos anos seguintes, marginalizou Trotski e seus seguidores, até eliminá-los. Após esses acontecimentos, a URSS mergulhou numa situação política, social e econômica que, se não pior, era muito semelhante àquela anterior à revolução. Isso gerou uma grande desilusão para os idealizadores de um estado socialmente igualitário e economicamente desenvolvido com base nos princípios marxistas. 
É nessa atmosfera, que Animal Farm é concebido e, embora, inicialmente, o texto remeta a uma estória de estrutura simples e de uma aparente facilidade de compreensão semelhante a uma fábula, tendo um cunho moralizante, com animais como personagens nessa obra, estão presentes alguns aspectos do cotidiano autoritário; podendo ser feita uma referência quase que imediata com o Stalinismo e a situação da Rússia naquela época. No entanto, essa referência a fatores externos - Stalin, Trotsky, Rússia - não é suficiente para a compreensão do todo da obra em nível de sentido, ou seja, para interpretar a obra é necessário ir além do mero reconhecimento das características do social nela presentes.

Candido (2000, p. 4) afirma, em sua obra Literatura e Sociedade "que o externo (no caso, o social) importa não como causa, nem como significado, mas como elemento que desempenha certo papel na constituição da estrutura tornando-se, portanto, interno". O autor também faz referência "a uma interpretação estética que assimilou a dimensão social como fator de arte" (2000, p. 7) para mostrar como deve ser analisado o fator social dentro de uma obra literária. Por isso, para compreender o sentido da obra é necessário reconhecer as evidências concretas exercidas pelos fatores sócio-culturais sobre a mesma em seu nível interno, considerando que o texto literário toma aspectos da realidade e os devolve de uma maneira caracterizada pela modalidade discursiva da arte literária.

O surgimento da nova forma de sociedade em Animal Farm se deu a partir de um objetivo exposto de forma profética por um velho porco chamado Velho Major. Isso pode ser identificado no fragmento seguinte do discurso dessa personagem:

Eu tive uma longa vida, eu tive muito tempo para pensar, posto que eu durmo sozinho na minha baia e eu penso que posso dizer que entendo a natureza da vida nesta terra tão bem quanto qualquer outro animal vivente. É sobre isso que quero falar com vocês. [...] nossas vidas são miseráveis, trabalhosas e ínfimas [...] Porque nós continuamos nesta situação miserável? Porque praticamente quase tudo o que nós produzimos com nosso trabalho é roubado pelos seres humanos [...] Era um sonho de como a terra será quando o Homem tiver sido exterminado ${ }^{1}$. (ORWELL, 1982, p. 8 e 12).

É possível identificar a representação simbólica na obra e fazer uma analogia com a maneira que muitos estados totalitários surgiram, isto é, a partir de uma personagem visionária que tinha aparentemente, em princípio, boas intenções; mas que teve os seus objetivos distorcidos pelo interesse daqueles que fizeram uma leitura da doutrina inicial que melhor lhes aprouvesse. É também possível identificar como a luta entre classes e a busca por um culpado é presente.

É importante analisar e interpretar o significado do discurso do velho Major, isto é, no começo da estória, a idéia inicial é colocada como algo que está em um nível abstrato, quase

\footnotetext{
${ }^{1}$ Todas as citações foram traduzidas pelo autor do artigo.
} 
profético, não fazendo referência ao caráter pragmático de um objetivo. Quando a idéia primeira é colocada dessa maneira, percebe-se que inicialmente as coisas não foram apresentadas como um objetivo planejado empiricamente. Novamente, podemos considerar esse fato como uma referência ao modo como foram concebidos muitos estados totalitários.

No texto do romance, os dominadores criam determinadas estratégias ideológicas para que os dominados se submetam e se comportem de acordo com os objetivos da classe dominante. Por exemplo, na seguinte passagem do capítulo VI: "Todo esse ano, os animais trabalharam como escravos; mas eles estavam felizes em seu trabalho, eles não poupavam esforços ou sacrifícios, eles estavam convictos que tudo que eles fizessem era para o seu próprio benefício e daqueles que viriam depois deles.” (ORWELL, 1982, p.53).

$\mathrm{O}$ narrador começa mostrando como os animais estavam sendo manipulados e ludibriados pela ideologia pregada pelos dominadores - sentimento de igualdade, de proveito comum - e como esses animais eram realmente tratados como escravos. Nesse segmento, podemos remeter à situação a que são submetidos os elementos de uma realidade social, na qual a ideologia das classes dominantes dá o embasamento lógico e aceitável sócioculturalmente para as situações de exploração e de repressão dos dominados.

Os aparelhos ideológicos utilizados pela classe detentora do poder, representados em Animal Farm, evidenciam aquilo que Althusser (1996), em seu ensaio Ideologia e Aparelhos Ideológicos de Estado, chamou um certo número de realidades que se apresentam ao observador imediato sob a forma de instituições distintas e especializadas, que seriam o religioso, escolar, jurídico, político, da informação - imprensa, cultura. Segundo Althusser, esses aparelhos ideológicos do estado funcionam pela ideologia.

Uma análise minuciosa do discurso dos governantes da fazenda Manor comprova isso, ou seja, criou-se uma ideologia para justificar as atitudes repressivas do novo estado totalitário que surgia. Por exemplo, num segmento do capítulo VIII, em que, após a execução de vários animais - galinhas, gansos e porcos - devido às suas atitudes, aos seus questionamentos, supostamente subversivos frente à política do estado, representado na figura de Napoleão, os animais lembravam ou pensavam lembrar do sexto mandamento, o qual tinha sido alterado:

Poucos dias depois, quando o terror das execuções tinha sido amenizado, alguns animais se lembraram- ou pensaram ter se lembrado- que o sexto mandamento decretava: Nenhum animal matará qualquer outro animal. [...] Muriel leu o sexto mandamento para ela. Ela leu: Nenhum animal matará qualquer outro animal sem justificativa. Em algum lugar, as últimas duas palavras tinham sido retiradas da memória dos animais. (ORWELL, 1982, p. 78). 
É possível perceber a maneira como foram sendo modificados os princípios ideológicos iniciais e como isso se aplica a maioria dos governos despóticos que se desenvolveram durante toda a evolução histórica da humanidade. Podemos reconhecer o tom sarcástico do narrador ao mencionar que os animais pensavam se lembrar de determinado acontecimento, mas sem um grau de certeza. Observa-se que, gradualmente, os animais esquecem do que lhes fora prometido ou, quando liam as alterações das regras que regiam a vida animal, não se davam conta das modificações dos ideais, que, em algum lugar da memória, haviam perdido. Fica claro como as estratégias ideológicas modificaram a imagem da realidade.

O sentido de Animal Farm vai além da simples correlação simbólica da Rússia de Stalin e a Revolução dos Animais da Fazenda Manor; ela atinge um caráter de significação maior que uma comparação pontual com um aspecto histórico, sendo possível reconhecer uma amostra de como se portam as relações de poder em diferentes sociedades. Nessa perspectiva, pode-se perceber como a arte literária lida e veicula essa questão, se adequando ao contexto do leitor e adquirindo novas significações.

O romance aponta a incapacidade humana em lidar com o poder que transcende o simples plano da exemplificação através de modelos políticos históricos específicos e acaba por ser uma característica inerente ao ser humano, pois o desenvolvimento desses modelos cai no eterno ciclo de repetição dos quais tentaram escapar.

No final da obra, o narrador coloca a situação a que chegaram os líderes dos animais, os porcos:

Doze vozes estavam gritando em tom de irritação, elas eram todas parecidas. Agora não havia nenhuma dúvida sobre o que tinha acontecido na face dos porcos. Os animais do lado de fora, olhavam dos porcos para os homens e dos homens para os porcos, e novamente dos porcos para os homens; mas já não era mais possível dizer quem era quem. (ORWELL, 1982, p. 120).

Nessa passagem fica clara a situação a que chegou a sociedade estabelecida com princípios que deveriam ser baseados na justiça e na igualdade. Os governantes - no caso, os porcos - se tornaram tão semelhantes àquilo que tanto criticaram, ou seja, os desmandos e a opressão humana que se tornou impossível reconhecer onde estavam às características de cada um. Porcos e humanos pareciam iguais uns aos outros.

Pode-se reconhecer o que Adorno, referindo-se às imagens positivas de uma sociedade adequada, cita em seu texto Mensagens numa Garrafa: "todas as utopias sociais, desde a de Platão, fundem-se numa desalentadora semelhança com aquilo contra o qual foram concebidas. O salto para o futuro, passando por cima das condições do presente, aterrissa no passado." (ADORNO, 1996, p. 64). 
E é esse processo de saltar para o futuro e aterrissar no passado, essa incapacidade de mudar, características dos estados constituídos, que podemos identificar como um sentido mais amplo do referido romance de Orwell.

O que fica evidente na obra é que a relação entre a classe dominante e a classe dominada se mantém presente em qualquer contexto social, pois sempre, ao longo da evolução histórica, existiram as relações de poder onde os controlados vivem a mercê daqueles que os controlam até desenvolverem estratégias de resistência para se fazerem ouvir e modificar, gradativamente, as formas de sentido e valor do segmento dominante. $\mathrm{O}$ que a obra parece mostrar é que existe uma tendência geral daqueles que detém o poder em manterse no poder e reproduzir a ordem social dominante, isto é, quando uma classe atinge uma posição de domínio, ela parece fazer uso dos mesmos artifícios que os seus antecessores usaram antes dela e isso transforma a sociedade em um local de confronto dos diferentes segmentos sociais, isto é, o meio social torna-se um local de exclusão e inclusão onde as classes menos favorecidas são ludibriadas pela ideologia dominante da classe privilegiada.

\section{Conclusão}

É possível concluir que o texto literário tem a capacidade de estar inserido num contexto social e, simultaneamente, retratar através do discurso ficcional essa realidade. No entanto, pode-se perceber através da análise da obra Animal Farm que o sentido de um texto literário vai além da simples ligação entre o seu contexto de origem e a sua estória.

Animal Farm, embora reitere uma critica contra o regime totalitário e intransigente de Stalin, não fica restrito a esse contexto específico. O romance adquire uma significação que se adapta em diferentes momentos da história do desenvolvimento da humanidade, pois representa uma característica inerente aos seres humanos: a incapacidade de lidar com o poder.

\section{Referências}

ADORNO, Theodor. Mensagem numa garrafa. In: ZIZEK, Slavoj. (Org.) Um mapa da Ideologia. Tradução de Vera Ribeiro. Rio de Janeiro: Contraponto, 1996.

ALTHUSSER, Louis. Ideologia e aparelhos ideológicos do estado. In: ZIZEK, Slavoj. (Org.) Um mapa da Ideologia. Tradução de Vera Ribeiro. Rio de Janeiro: Contraponto, 1996. 
FIORIN, José Luiz. Ideologia e Linguagem: 2. ed. São Paulo: Ática, 1990.

MELLO E SOUZA, Antonio Candido. Literatura e sociedade: estudos de teoria e história literária. 8. ed. São Paulo: T.A. Queiroz, 2000.

ORWELL, George. Animal Farm a Fairy Story. New York: Penguin Books; Martin Secker \& Warburg, 1982.

ZIZEK, Slavoj. (Org.) Um mapa da ideologia. Tradução de Vera Ribeiro. Rio de Janeiro: Contraponto, 1996. 